\title{
GLOBALIZAÇÃO: ANTROPOLOGIA E RELIGIÃO
}

Otávio Velho*

A percepção da globalização como um evento histórico, suscetível de ser tratado como objeto de investigação, encontra entre os antropólogos grande resistência, seguidamente ocultada para o público externo pela presença significativa, nos debates interdisciplinares, de um pequeno grupo de especialistas, dentre os quais se destacam figuras como Ulf Hannerz, A rjun A ppadurai e J onathan Friedman. Essa resistência, aliás, é análoga justamente à apresentada às posições que nos anos 50/60, retomando tendências anteriores que atravessavam o espectro político-ideológico, acentuavam a centralidade e a inevitabilidade dos processos de desenvolvimento e modernização, tornando desse modo bastante problemáticas, por exemplo, as relações da antropologia com o marxismo. Podese dizer que na permanente oscilação do pêndulo lluminismo-Romantismo, no que diz respeito a essa questão, a antropologia tendeu a filiar-se ao pólo romântico dos grandes debates ocidentais, especializando-se numa espécie de contradiscurso em nome dos "seus" nativos e "suas" culturas, o que no Brasil encontrou plena justificativa na defesa das populações indígenas. Desse ponto de vista, as discussões sobre globalização seriam basicamente percebidas como não acrescentando nada de particularmente dramático às polêmicas anteriores. A retórica antropológica dominante procuraria manter-se imune a mais esse desafio, relegado para o plano da empiria.

Não há dúvida de que há muito de defensivo nessa postura, o que é compreensível. Compreensível, sobretudo, dadas as dificuldades aparentes em encontrar uma linguagem (e uma política) compatível com a tradição da disciplina no tratamento da questão, quiçá dado o ethos romântico acima referido e o receio de ver uma identidade ser ultrapassada, já que esta se apoiaria numa prática (a etnográfica) por suposto situada em pólo distinto de qual quer globalização. Não há dúvida, também, de que aqui estaríamos muito próximos de uma ilusão típica dos antropólogos, 
contraposta às ilusões de outras disciplinas das chamadas ciências sociais, que costumam ir em direção contrária, cativas das ideologias da modernidade. $\mathrm{M}$ as, ao mesmo tempo, essa postura pode ser instrumentalizada, seja no sentido de servir de alerta contra as versões mais simplificadoras, unidimensionais e reducionistas presentes na literatura sobre globalização, seja contra seus usos políticos e ideológicos. E mais ainda: na medida em que, como já foi sugerido por J ames Clifford, a antropologia se encontra em posição particularmente vulnerável e reveladora diante das crises contemporâneas (como a descolonização, por exemplo), os seus dramas disciplinares podem ser eles próprios fontes privilegiadas para se compreender a globalização, tal como se tentará mostrar adiante por intermédio de um debate recente.

Todavia, a hipótese da qual se pretende partir aqui é a de que haveria um parentesco de fundo - que as polêmicas simultaneamente ocultam e reforçam - entre o conservadorismo antropológico e parte considerável da literatura sobre globalização. E esse acordo poderia ser resumido dizendo-se que em geral o que se disputa é simplesmente a definição do que é determinante - se o local, o global ou alguma combinação dos dois -, sem que se discutam os próprios termos da questão e a natureza imaginária dessas objetificações; ou seja, sem assumir que estamos diante de realidades inseparáveis da própria ação humana.

Uma sugestão inicial, sem que outras possibilidades fossem excluídas, poderia ser pensar a questão da globalização em termos de perspectiva. Para os que, em geral, se dedicam à questão, isso levaria a pôr um grão de sal na ênfase exclusiva nas periodizações e descontinuidades, que fazem ignorar em larga medida a problemática antiga das interdependências, bem como o caráter histórico dessa problemática, sujeita, aí sim, a descontinuidades, ciclos e retomadas óbvias que desmentem qualquer sentido evolutivo. Isso permitiria relativizar as descontinuidades sem ter de cair no pólo oposto, substantivista, da polêmica e sem ter de negar as novidades que se impõem. Ou seja, poder-se-ia pensar a "globalização" (ou as interdependências), no limite, em qualquer situação; ou, alternativamente, poder-se-ia colocar a questão entre parênteses. $O$ "novo" de hoje só o seria na medida em que se considere que recaptura de modo fértil o passado; mas, ao fazê-lo, paradoxalmente o efeito será relativizar-se enquanto "novo". Do lado dos antropólogos, isso significaria obrigar a uma leitura mais detida da sua tradição, na medida em que se teria de enfrentar não apenas os desafios de um novo objeto, mas a desnaturalização (ou desconstrução, se se preferir) de uma série de hábitos profissionais, com repercussão na avaliação da própria história da dis- 
ciplina, sobretudo na de algumas tendências hoje dominantes que, vencedoras de antigos embates, ocultam outras possibilidades.

Curiosamente, até diria que em certa medida esse descongelamento tem se dado. M as não em nome da globalização. A fora o fato de vir a confirmar que os antropólogos preferem fazer prosa sem declará-lo (o que é diferente de não sabê-lo), isso faz supor que uma análise do que vem ocorrendo poderia sugerir aos pensadores da globalização - num esforço reflexivo - um modo de enquadrar o seu próprio discurso nos desenvolvimentos intelectuais contemporâneos, escapando dos riscos de uma pretensão totalitária e de uma espécie de fim da história intelectual, em que "globalização" (tal como, em outros contextos, "cultura") parece invariavelmente servir como última palavra. M esmo porque, dado exatamente o estilo dos antropólogos, essas alterações ocorridas na disciplina podem ser vistas como reações (e sintomas) mais ou menos imediatos a alterações nos seus próprios objetos. $\mathrm{Ou}$ - pondo de forma mais dialogicamente "correta" e que desconstruiria a tradicional categoria de "informante" - podem ser vistas como alterações nas interlocuções constitutivas do seu trabalho, que em função de sua recorrência e abrangência empíricas são suscetíveis, por sua vez, de serem remetidas para o âmbito do "global". Para utilizar um exemplo que será privilegiado no presente texto, seria o caso, em matéria de alteração da experiência, quando os antropólogos vêem nas mais diferentes regiões do mundo os "seus" nativos going pentecostal, alterando ou substituindo usos que Ihes pareciam (aos antropólogos) essenciais.

Em benefício da síntese, um breve resumo de uma polêmica recente será utilizado aqui para ilustrar algumas das questões hoje enfrentadas pela disciplina.

Um dos mais ilustres antropólogos contemporâneos, M arshall Sahlins, da Universidade de Chicago, dedicou-se numa série de escritos a interpretar a partir do seu conhecimento da cultura havaiana os eventos que redundaram na morte do famoso explorador e navegador inglês, o capitão J ames Cook, em 1779 (ver, entre outros, Sahlins 1982). Ao fazêIo, desenvolveu com maestria uma abordagem que pretendia ser capaz de fazer justiça simultaneamente à estrutura e à história, buscando romper com a aparente oposição entre ambas que constitui desafio permanente para as ciências sociais. E mostrou como a adoração de Cook como um deus (Lono) se articularia com a sua morte, física, mas também ritual.

Em 1992, o antropólogo Gananath Obeyesekere, da Universidade de Princeton e natural do Sri Lanka, publicou um livro em que polemizava com Sahlins e questionava a suposta adoração de Cook pelos "nati- 
vos" (Obeyesekere 1992). Reanalisando o material, concluiu que a adoração poderia ser uma construção ex post, baseada na projeção da adoração de Cook pelos próprios europeus. A presentou, ainda, uma visão alternativa do comportamento nativo, segundo ele, objeto - em nome justamente da "cultura" - de uma fixação infantilizadora a que não seriam imunes os antropólogos. $\mathrm{N}$ a verdade, para Obeyesekere o comportamento nativo no episódio poderia ser perfeitamente entendido em termos pragmáticos e políticos, os europeus (e o próprio Cook) não se dando conta do quanto eles próprios eram regidos por " mitos" (no caso, o da adoração do homem branco pelos nativos) - a noção de mito, aliás, sendo, ironicamente, de origem européia.

O beyesekere não pretendia, propriamente, demonstrar uma tese, mas lançar dúvidas sobre uma explicação única, na medida em que revelava sua natureza em grande parte especulativa e na medida em que interpretações alternativas pudessem se mostrar razoáveis. Certamente, porém, nessa operação era movido por um sentimento de indignação pelo que Ihe parecia mais um episódio de prepotência ocidental, tanto na substância (a adoração de Cook), quanto na forma (a pretensão demonstrativa).

Em 1995, Sahlins reagiu. Descontada a virulência da linguagem, a reação se deu em nome do desmonte do que seria uma pretensão (também) de uma posição ideológica que se autoproclama " politicamente correta" e de uma desconsideração das especificidades culturais em nome de universais do comportamento (Sahlins 1995).

Esta é uma discussão extremamente densa. Para os presentes propósitos, interessa inicialmente indicá-la como sintoma das dificuldades de relacionamento de uma disciplina estabelecida - mesmo tratando-se da "indisciplinada disciplina" de que fala Clifford Geertz - com correntes gerais de pensamento que refletem mais imediatamente e com menor resistência as tendências da época. A partir dessa visada, embora isso não seja explicitado nem, talvez, intencional, pode-se dizer que Obeyesekere faz reverberar no interior da antropologia algumas preocupações que têm sido organizadas em torno da noção de "pós-colonialismo". E Sahlins responde em nome da tradição (na verdade, uma versão hegemônica) disciplinar. A dificuldade para Obeyesekere está, então, em contestar mantendo-se nos limites da linguagem legítima, ainda mais sendo o seu adversário considerado um dos expoentes do campo. Tem-se a sensação de que o resultado da contestação é, até certo ponto, decepcionante, quase caracterizando uma incomensurabilidade intransponível. Obeyesekere não pode - nem se fica sabendo até que ponto as domina - 
utilizar as referências pós-coloniais, ficando numa espécie de meio caminho entre elas e o mais antigo terceiro-mundismo, o qual, traduzido no interior da antropologia, redunda em certo arcaísmo, como no caso do apelo ao universalismo.

$\mathrm{N}$ a verdade, isso não significa dizer que não haja comunicação entre a antropologia e as correntes menos disciplinares de pensamento, seja sub-repticiamente, seja através de mediadores (não necessariamente reconhecidos como tais) respeitados. Como já indicamos, os antropólogos têm se revelado mestres na arte de fazer prosa sem declará-lo, com isso avançando sel etiva e camufladamente, sem "dar o braço a torcer", buscando não abalar os alicerces da disciplina. Agora, porém, a questão é mais séria. E uma das razões é que está sendo discutida justamente a noção de cultura, tão associada à identidade disciplinar: por um lado, sendo revista; por outro, sendo objeto de múltiplas apropriações que provocam sensação de perda de monopólio (até no mercado de trabalho), expressando-se tal sensação na forma de uma demanda por ordem. Nessas circunstâncias, corre-se o risco do avanço camuflado ser substituído por fundamentalismos disciplinares reativos - o retorno do mito, nos termos sugeridos por Obeyesekere para os europeus. Sobretudo porque não se trata tanto de que antes houvesse de fato um monopólio, e sim que agora a antropologia está sendo expressamente citada, por vezes criticamente, o que dificulta a postura de indiferença.

Há, de fato, desafios sérios no ar. E o primeiro deles talvez redunde do próprio sucesso de uma sensibilidade com a qual a antropologia se identificava e que hoje se generalizou. General izou-se, por exemplo, na preocupação com a diferença e contra as ambições excessivas da teoria. Como se a antropologia tivesse sido uma "vanguarda" que aos poucos foi alcançada e, assim, de certo modo, dissolvida enquanto tal. Indicativa é não só a "virada cultural" dos anos 80 , mas também a disseminação do interesse pela etnografia. Como ainda o volume de publicações "transdisciplinares" e a aplicação da questão da diferença não só para localizar o outro "externo", mas para pensar as diferenças internas às sociedades, aos grupos, aos indivíduos para muito além do que poderiam imaginar os clássicos da antropologia e quase que desconstruindo por exacerbação a própria noção de cultura.

Portanto, estamos diante de dois desenvolvimentos que por assim dizer se atropelam. Por um lado, a antropologia foi como que alcançada. O saber antropológico tornou-se em amplos círculos uma espécie de lugar-comum, o que em certos casos é mesmo mais um exemplo da quebra pós-moderna da distinção entre alta e baixa cultura. Por outro lado, a 
antropologia vai sendo contestada de um modo diferente do praticado pelo bom e velho etnocentrismo que ela se acostumara a ter como adversário; a ponto de por vezes ela mesma, ironicamente, ser acusada de etnocentrismo e de representante de um olhar externo.

No que diz respeito ao primeiro ponto, não deixa de ser interessante verificar sua relação objetiva com a globalização, que levaria a uma tendência a uma espécie de "relativismo generalizado" (ao lado, evidentemente, das reações fundamentalistas), ao reconhecimento vivido e necessário das diferenças, à experiência da natureza artificial e construída das culturas etc. M as ao mesmo tempo, e analogamente, assim como os antropólogos perdem certos monopólios, certos atributos da sociedade ocidental que ajudaram a construir são também contestados enquanto qualificação de exclusividade: individualismo, reflexividade etc. Contestados, inclusive, como capacidade supostamente única de produzir uma antropologia. E isso leva à questão da contestação da própria antropologia, que em certos círculos foi transformada de vanguarda em cúmplice de uma ideologia dominante e etnocêntrica.

A fora a necessária consideração do papel dos jogos e dos compromissos estritos de poder para entender a situação, uma outra maneira de abordar a questão seria negar a afirmação feita pela narrativa antropológica de que a sociedade ocidental seria portadora de uma incapacidade fundamental de reconhecer a diferença. E, pelo contrário, indicar que o estabelecimento da alteridade sempre foi uma operação crucial, reproduzida pela antropologia. É essa indicação que tem sido feita, por exemplo, pelos críticos do Orientalismo e pelos autores pós-colonialistas, para apontar o que existe de discriminatório, em última instância, nessa operação. Isso é de certa forma o que também faz Obeyesekere. Só que possivelmente a tendência mais interessante no momento não seja a de retorno a um discurso universalista (que talvez tenha sido utilizado por Obeyesekere justamente por ter um lugar na história da disciplina), mas de um discurso oposto: o das semel hanças e das aproximações contingentes. Oposto, também, por outro lado, ao discurso das diferenças reificadas que na verdade não leva às últimas conseqüências a discussão da alteridade - , contestando, assim, uma exótica da diferença. Obeyesekere pode, de fato, estar mais próximo dos havaianos do que Sahlins; mas, simplesmente, em função de uma narrativa que assim o postula e estritamente na medida do poder (contingente e relativo) dessa narrativa - em concorrência com as demais - de refigurar o mundo.

Esse discurso das semelhanças, dando ênfase ao contingente, não anularia a diferença, apenas a sua exótica. Pelo contrário, estaria asso- 
ciado a um estranhamento que incluiria reflexivamente a nossa própria condição, movimento do pós-estruturalismo que a antropologia como disciplina efetivamente jamais chegou a realizar até as últimas conseqüências. Estas incluiriam um questionamento da própria disciplina e um deparar-se com os limites do "tornar familiar" que, na medida em que o outro deixe de ser reduzido ao al heio, pode levar ao reconhecimento de um si mesmo que constitua uma consciência moral (Ricoeur 1995). Paradoxalmente, só a plena aceitação do estranhamento permitiria a sua incorporação, inclusive no plano moral. A experiência da natureza artificial e construída da cultura feita "em casa" alteraria o efeito de distância provocado pelo estranhamento do "outro". Levaria a um reencontro com a "humanidade" e a uma diferença que, apostando num mundo descentrado, se associaria menos à hierarquia (como se tornou lugar-comum na antropologia postular) e mais - sem conotações "filosóficas" abstratas ao diálogo e, conseqüentemente, à pesquisa de semelhanças que aproximem, mesmo na "interlocução" científica com os "objetos". Inclusive poderia levar a um diálogo interior, alterando a própria vivência da pessoa.

Aí, talvez, estivéssemos, para além da descrição objetivista, caminhando no sentido da detecção de um desejo de semelhança, mimesis ativa caracterizada mais pela exploração do desconhecido que pela tentativa de reprodução de um modelo que se interromperia na confrontação com a diferença (Costa Lima 1995). A té para refocalizar como "problema" elementos da cultura anteriormente naturalizados - como começa a acontecer no Brasil no caso das relações raciais e de gênero -, mesmo tendo-se que buscar minimizar as perdas e os eventuais empobrecimentos de visão daí decorrentes, tentando manter o reconhecimento das especificidades e da produtividade dos mitos na construção de identidades culturais. A crença no entendimento racial brasileiro, por exemplo, não pode ser reduzida a mero embuste, justamente podendo ser articulada a essas tendências, embora complexificando o próprio discurso da especificidade. As multiplicidades identitárias permitiriam na interação a opção pela apresentação daquilo que aproxima. Como se diplomacia e civilidade substituíssem, de modo menos pretensioso, autenticidade e cultura, num novo momento, pós-moderno, da busca de caminhos para a convivência humana. M as que, curiosamente, reencontra - e desse reencontro se falará mais adiante - uma linguagem bíblica da exaltação do semel hante, figura a meio caminho entre o diferente e o igual.

Essa possibilidade de reconstituição, não baseada a priori, da humanidade seria um pano de fundo da globalização, detectável nas discus- 
sões sobre a "universalidade" dos direitos humanos, por exemplo. Essas discussões costumam pegar os antropólogos no contrapé, lentos em apreender a sofisticação e a atualidade das questões, buscando reduzilas à vel ha querela com o etnocentrismo. M as elas de algum modo vão sendo assimiladas, apesar das dificuldades, como a de se dar conta dos usos perversos do culturalismo, em choque com uma sensibilidade que busca se transformar numa civilidade planetária.

Uma das modificações ocorridas de modo lento, desigual e sem formalização na antropologia - talvez nos últimos quinze anos - é uma desconfiança crescente quanto à referência necessária a totalidades fechadas, que pressuporiam relações permanentes entre suas partes e em descontinuidade flagrante e oposição excludente - com o exterior. Um dos casos em que isso tem se manifestado - como que em relação metonímica com a "globalização" - é no desprestígio da noção de "tribo"; iniciado na literatura africanista, hoje esse desprestígio também se manifesta na etnologia sul-americana. Outro, mais abstrato, é o das revisões da noção de cultura, com a demanda por concepções menos reificadas e que levem em conta uma dinâmica que inclui a sua permanente "invenção" e o poder da ação humana como geradora de cultura - mesmo para permanecer, o que revelaria a fragilidade da impressão de imobilismo. Assim, inverter-se-ia o padrão de expectativas consagrado, que seria o da cultura como dado prévio, "superorgânico", retomando-se na direção do expressivismo uma tensão entre concepções que, na verdade, já estava presente desde o Romantismo alemão. Associado a isso há o reaparecimento de noções como hibridismo e sincretismo, sempre presentes de alguma forma em outros discursos, como o do "pensamento social brasileiro", mas até há pouco banidas por uma espécie de padrão estético naturalizado da antropologia mais prestigiada. E esse reaparecimento é significativo, mesmo quando tais noções são tratadas mais como discriminadoras do que como constitutivas de uma dinâmica cultural mais ampla, não se apagando, ainda, certo vestígio de exoticismo e de privilegiamento da "autenticidade".

Relacionada a essa alteração, há uma ênfase crescente nos processos e nas interconexões concretas, quase como uma retomada do difusionismo, mas ganhando relevo as contingências, as negociações e os acordos entre os grupos sociais. N os embates internos à disciplina, essa ênfase é por vezes contestada com a acusação de que o que se propõe com ela é que por detrás de cada pardo haja sempre um branco. M as, na verdade, isso só é crível quando não se reconhece que se está diante de um elaborado jogo de espelhos, onde outras possibilidades estão igualmente 
colocadas, tal como é dramatizado pela atual (já houve outras) onda de invasão do centro pela periferia. Abre-se todo um campo para uma discussão não essencialista da cultura, onde, por exemplo, os orientalismos podem, por sua vez, ser apreciados na sua inversão, evidente em casos como o do Brasil, constituído como um lugar das fantasias e do imaginário europeus, mas sem dúvida dentro de um complexo e cúmplice jogo de reciprocidades (Velho 1995a).

Essas novas tendências, como já mencionado, têm ressonância nas próprias concepções da pessoa. Esta é cada vez mais percebida como complexa, a ponto de serem abaladas - tal como vem também ocorrendo através de outras linhas de reflexão - as noções fixas de identidade, construídas por meio de oposições. Acentua-se a tentativa por vezes agonística de acionamento de outros mecanismos (como o da busca de semeIhanças e aproximações contingentes, acima referida), de novos recortes (por exemplo, apoiados em estilos de consumo e/ou etnicidades), de múltiplos pertencimentos e reconhecimentos ("tribais", por exemplo, em sentido tradicional ou derivado) e distintos graus de engajamento e compromisso. Ironicamente, poder-se-ia indagar se Gananath Obeyesekere, mais do que somente antropólogo e partícipe de um diálogo intelectual, não seria uma personagem que dramatiza e performatiza essas múltiplas possibilidades e tensões, como scholar pós-colonial do establishment acadêmico do Primeiro Mundo.

Também se tem acentuado o papel da reflexividade e da competência relativizadora na constituição e reconstituição das identidades sociais, como entre nós no Cone Sul da A mérica Latina parece começar a se manifestar, com o esforço de revisão da história regional (dramatizado em certos casos emblemáticos, como o que no Brasil denominamos de "Guerra do Paraguai"), provocado pela constituição do M ercado Comum do Sul (M ercosul). E que já chega a complexificar na prática (globalization at work, diria Hannerz) noções sacralizadas de soberania nacional. Tudo isso, evidentemente, tendo relevância para a questão da relação sujeitoobjeto nas próprias ciências sociais.

A relação entre "social" e "cultural" tem igualmente estado sujeita à revisão. Fenômenos como o desenvolvimento do pentecostalismo nas mais diversas regiões do mundo (inclusive no Brasil, não faz muito tempo considerado como o exemplo por excelência de uma cultura católica de vocação holística) não podem ser desqualificados simplesmente pressupondo-se absoluta capacidade de absorção e domesticação locais do que vem de "fora", sem resíduos. M esmo quando resta uma insatisfação com as alternativas "globais" colocadas - igualmente insensíveis, em geral, 
às variações e às contingências - , a retórica que sugere essa absorção e domesticação plenas permanece, mas soa cada vez menos convincente. Sobretudo, talvez, num caso como o da religiosidade, em que o apelo para o transcendente legitima o desrespeito às fronteiras, constituindo a história das chamadas "religiões mundiais" exemplo claro (uma vez que nos coloquemos na perspectiva adequada) de que não estamos apenas lidando com um novo objeto entre outros. Isso, evidentemente, sem negar a importância do aumento contemporâneo do repertório das religiões potencialmente mundiais, propiciado pelos novos meios de comunicação (questão que também pode ser tratada na perspectiva da globalização) e pela extensão sem limites da possibilidade de fixação de tradições sagradas através da escrita a que nem sempre é al heio - como no caso dos "cultos afro-brasileiros" (e, hoje, dos afro-brasileiro-argentinos, uruguaios e luso-afros) - o próprio trabalho dos antropólogos.

A lterações como essas podem ser e têm sido explicadas em termos de avanço do conhecimento e de aperfeiçoamentos metodológicos, produtos da própria prática de pesquisa. Essa - e não simplesmente sua rejeição - parece que tende a ser a nova linha de defesa disciplinar. M as será, então, por mera coincidência que esses desenvolvimentos encontram paralelo em outros domínios? J á se disse que os nativos da década de 40 pareciam todos funcionalistas; hoje, começam a parecer pós-estruturalistas.

Sem nos rendermos à hipótese inversa - a de que somos todos tributários dos filósofos e epistemólogos do momento -, explicação mais plausível parece ser a de que estamos diante de tendências que atravessam diferentes domínios, disciplinas e, talvez, sobretudo a consciência comum, em complexa inter-relação. Quanto a esta última possibilidade a de uma tendência que passa pela consciência comum - exemplo talvez inesperado, mas por isso mesmo relevante para a antropologia no Brasil (e não só), é o caso já mencionado da pentecostalização. Estamos aqui bastante distantes de uma tendência predominantemente fundamentalista. O fundamentalismo, seguidamente, e não só nesse caso, está mais nos olhos, ouvidos e interpretação linear - ingênua e acusadora ao mesmo tempo - dos próprios observadores, crentes em uma realidade literal anterior às narrativas. E isso até chamaria a atenção para a demanda por uma postura alternativa por parte dos observadores. Alternativa tanto à explicação externa quanto à assunção do discurso nativo; mais dialógica e, quiçá, "terapêutica”, não excluindo a possibilidade de transformação, como produto da própria interlocução ou pelo menos como parte de processos sociais mais amplos dos quais essa interlocução faça parte. 
A oposição radical entre as figuras de Deus e do Diabo, no caso do pentecostalismo, ao invés de maniqueísta, parece interpretável como sendo um veículo e operador que hoje - com o chamado neopentecostalismo - pode ser acionado para fornecer a garantia necessária, por uma espécie de troca, para desfazer outros dualismos e essencialismos (sem falar das culpas). Isso se daria na forma de uma disputa de posições, vivenciada como busca de permanentes tomadas de posse, que constitui verdadeira guerra, total e de movimentos. Entre esses dualismos suscetíveis de serem desfeitos - ou pelo menos descongelados e repostos no campo da polêmica - estariam, então, a separação entre dois mundos incomunicáveis e, em cada um deles, a separação entre o lugar do bem e o do mal e o das valorizações e das desvalorizações. Desse modo, o terreno das contingências, do aqui e agora e do cotidiano ganha em centralidade. M uito além, inclusive, de simples locus dos sinais da salvação em outro mundo, constituindo-se aparentemente novo equilíbrio com as tendências milenaristas tradicionais. Estas não desaparecem, mas ganham função, por assim dizer, mais sutil e transformada, reconciliando-se a clássica oposição entre religiosidades de possessão (em que o tempo se identificaria com um eterno presente) e religiosidades messiânicas (voltadas para a redenção).

Essa hipótese, se comprovada, emprestaria nova dignidade, por exemplo, à ênfase na "prosperidade". A prosperidade seria sinal de uma libertação que se confunde com a afirmação prática, não-ascética, da legitimidade da fruição dos bens mundanos, indicativa de uma bênção e, mesmo, em certas circunstâncias, de uma aproximação - e eis outro dualismo posto em questão - entre o humano e o divino. Deus é reconhecido enquanto partícipe de uma relação no sentido pleno, que passa, inclusive, por uma atitude de demanda por parte do ser humano, que expressa como que a dependência de ambas as partes e a dignidade do papel ativo da liberdade humana, num embate cósmico que transforma o próprio esforço de existir num imperativo moral no mais alto nível. E como não se trata simplesmente de especulação teológica, embora seja possível estabelecer algumas afinidades com certas linhas de desenvolvimento a partir da Reforma, no seu conjunto, tudo isso de fato representaria mudança mais revolucionária do que muitas que assim se postulam. Estaria em jogo, muito menos as polêmicas sobre a relação entre obra e graça e muito mais, uma vez reconhecidos os efeitos do descolamento e autonomização da prática mundana, a busca de uma nova linguagem religiosa que afirme e dê sentido a essa prática, mas reapropriando-a, agora em outro plano que não o da salvação. 
Por sua vez - ainda privilegiando o exemplo pentecostal -, entre os essencialismos suscetíveis de serem desfeitos estariam justamente os que se referem à própria natureza humana, à do dinheiro e ao sentido da pobreza e da riqueza. A reduzida presença explícita de uma teologia no sentido mais estrito (essa afirmação não podendo, por sua vez, ser vista de modo objetivista e exterior às disputas) aparentemente não prejudica transformações que uma perspectiva cultural ista fixista e isolacionista não imaginaria como desdobramentos possíveis da narrativa cristã. Essas transformações possivelmente estão em relação oculta "sincrética" com outras tradições, inclusive orientais, por via da crença no poder do pensamento, e seu desdobramento no poder da palavra, que no Brasil encontrou terreno fértil para se desenvolver. Isso Ihe emprestaria surpreendente parentesco com a "Nova Era" e com a literatura dita "esotérica" e a de auto-ajuda.

Esses desenvolvimentos, por outro lado, não parecem sem paralelo com o que vínhamos apontando acima na própria prática disciplinar da antropologia. E também não deve ser por acaso que a ênfase no Espírito (e, seguidamente, também na energia e na libertação) - agente invisível responsável pelas desreificações e pela dissolução das oposições - reaparece em distintas manifestações religiosas, desde o pentecostalismo até a já referida Nova Era, talvez o exemplo privilegiado, embora sacrificial - posto que difuso e de realização própria duvidosa - , de toda essa isomorfia. Isso parece se dar pelo menos ao nível do significante - o que não é pouco - , atravessando as mais diversas sociedades e culturas como uma espécie de "mal-entendido", produtivo na medida em que permita o prosseguimento de uma conversação.

É importante lembrar que, hermeneuticamente, em nenhum desses casos é possível detectar uma razão interna às diversas narrativas que tornasse necessária essa convergência. No caso do pentecostalismo, por exemplo, sua presença inicial caracterizava-se pelo ascetismo e pela desval orização do mundo, justo o oposto do que vem se revelando agora. É como se, de fato, estivéssemos diante de uma ampla e potencialmente "global" situação dialógica, mas que para ser plenamente entendida, e não banalizada nem esvaziada de sentido, precisaria ser posta no contexto de um pano de fundo de desejo de semelhança, presente e mediador até na constituição das diferenças, que, se não anula, faz um reparo às energias postas na dimensão do "interno", reificada na definição moderna de "domínios" e, mesmo, "culturas". Seu emblema antropológico por excelência poderia ser o cargo cult melanésio, ou pelo menos as suas análises, se é que cabe tal distinção. 
Se de fato estivermos, então, diante de um "espírito de época" (o velho Zeitgeist, noção cuja dificuldade, hoje, em termos de vocabulário, é óbvia), a globalização certamente não será estranha a essa tendência. Não será estranha seja em termos de objeto, seja em termos do privilegiamento contemporâneo aparentemente constrangedor da perspectiva da globalização - afinal, como foi colocado anteriormente, em princípio apenas uma entre as muitas perspectivas possíveis. E isso independentemente de gostos, oposições, resistências ou do uso explícito desse significante. Mas, ao mesmo tempo, ela não será externa e/ou superior a esse "espírito de época", mesmo sendo este entendido, ironicamente, menos como organização de uma totalidade a partir de um centro que se impõe, e mais como uma costura passível de ser imaginada por um observador. Essa liberdade sugeriria como que uma imitatio do "espírito" - para mantermos o mesmo significante e a hipótese da sua recorrência transversa que recuperaria positivamente eventuais "mal-entendidos" - 0 qual não apenas sopraria onde quer, mas também como quer.

Reconhecer essa associação poderá trazer implicações para o tratamento da globalização. Uma delas será deixar de vê-la como um "fundamento" a se opor a outros, e mais como um texto, um recurso cultural, acionável por diferentes agentes e em diferentes contextos. E, como tal, por um lado, incapaz de ser fixado num padrão único, homogeneizador ou não. Mas, por outro, incapaz de ser confundido com um "modismo", pois o modismo só pode ser caracterizado em oposição complementar a algum fundamento, que justamente estaríamos supondo inexistente. Ao contrário, a proposta é que estaríamos de fato diante de um mal-entendido produtivo, que exigiria a estratégia de construção de discursos próprios sobre a globalização, cada discurso constituindo como que uma recepção e apropriação do texto específicas, que por sua vez podem se transformar em texto. E isso em contraste com a estratégia de uma ilusória exterioridade que corre os riscos - como tem insistido Roland Robertson no conjunto da sua obra - da self-fulfilling prophecy na aceitação paradoxal e ressentida das versões dominantes da globalização, sobretudo as de caráter deterministicamente econômico.

No Brasil, contudo, as versões iniciais que vão nessa direção economicista (que hoje partem sobretudo do mundo da política) não têm sido capazes de dar conta de outras dimensões da questão que se impõem. É o caso da constituição de uma opinião pública "global" que - sem que se possa negar todos os jogos de força envolvidos - de algum modo demanda, como já mencionado, uma agenda e padrões de civilidade que, em sua assumida superficialidade, no entanto vão além de uma moderni- 
dade perfunctória e triunfalista. Na prática chocam-se com o culturalismo nas suas versões politizadas e ideologizadas, por vezes apresentadas na forma de nacionalismos em que se confundem posições tradicionalmente supostas antagônicas. Isso tem sido muito bem ilustrado pela repercussão internacional de violências cometidas contra menores, mendigos, idosos e camponeses no Brasil, obrigando a um realinhamento "interno" em torno dessas questões.

Embora não caiba minimizar o estranhamento diante daquilo que faut de mieux estamos denominando "espírito de época", alguns elementos subentendidos podem ser explicitados, tomando-se o campo religioso como referência. Alphonse Dupront (1993), no contexto católico, sugeriu que estamos hoje diante de uma corrosão da cultura cristã (uma descristianização) que impede a transmissão da mensagem religiosa por via da tradição. Diante dessa constatação, o movimento pentecostal e o carismático se imporiam: a volta do Espírito como sinal dos tempos, ultrapassando os limites de uma racional idade estabelecida. Coincidentemente, hoje no Brasil vem se falando na tendência à (neo)pentecostalização no conjunto do campo religioso. Suponha-se, pois, que seja possível reinterpretar a idéia de Dupront de quebra da tradição no sentido posto pela literatura atual sobre destradicionalização, a qual se identificaria menos com a simples quebra da tradição e mais com a reflexividade e conseqüente perda de alinhamento automático com a tradição, o que seria aparentemente próprio de uma hermenêutica, que interrompe o pertencimento ao mundo por tradição a fim de significar (Ricoeur 1995). Poderíamos, então, associar essa "pentecostalização" a outros elementos ligados à destradicionalização, como a ênfase no presente, nas diferenças, na experimentação, no indivíduo e na ruptura com a noção de representação. E, até, poderia ser associada, como se ilustrará adiante, menos a uma negação da cultura, e mais ao deslocamento já referido da noção de cultura numa direção expressivista, presente também na antropologia. Outros elementos tendenciais poderiam, então, ser agregados, como a relativização - realizada de modos certamente diversos e complexos da oposição público-privado e da oposição racionalidade-afetividade, esta última tendo repercussões até na área da pesquisa neurobiológica e da cognição.

Nessa linha, poderiam ser indicadas, ainda, as reflexões de Niklas Luhmann e de alguns sociólogos da religião (como Bryan Wilson, Peter Beyer etc.) que apontam no sentido de uma mudança nas "funções" da religião. M udança oculta, talvez, ao antropólogo por sua ilusão típica, já referida, que paradoxalmente pode conduzi-lo - a ele, o campeão das 
contextualizações - a certo nominalismo, aquém do reconhecimento de um "mal-entendido". Essa mudança levaria a religião, primeiro, a tender a deixar de ser integrativa e fundacional para reduzir-se a um subsistema; e, segundo, dadas as dificuldades de restrição a esse papel e a um vácuo deixado pela própria diferenciação estrutural moderna, a tornar-se disponível para outros papéis, mais amplos, porém agora de modo menos fundacional, orgânico e mais como recurso cultural (Velho 1996). Isso também pareceria apontar na direção de uma historicização radical, de uma maior fluidez e - performatizando o uso do vocabulário religioso como recurso - na direção de uma atenção aos sinais dos tempos e da bendição da contingência.

Parafraseando o vocabulário weberiano, curiosa e surpreendentemente poder-se-ia dizer que tudo isso vai muito mais na direção do "carisma" que da "racionalidade". Embora, por analogia com o tratamento que faz Michel Foucault da sexualidade, se possa imaginar que para além dessa oposição - por vezes radical e mesmo traumática em termos de experiência prática - se esteja na verdade propondo uma outra organização da racionalidade e um vocabulário alternativo onde Zeitgeist (espírito do tempo) e Geistzeit (tempo do espírito) se identificariam.

No campo religioso, a outra face da pentecostalização poderia ser, como já indicado, uma generalizada “desteologização" que não se restringiria aos grupos ditos pentecostais. Mas na verdade, até dentro do espírito de Pentecostes - "o Espírito sopra onde quer" - a pentecostalização poderia por sua vez ser aproximada de outras experiências afetivas fortes, como as associadas em geral aos "estados alterados de consciência" e à "libertação". Libertação, aliás, também comprometida com outro elemento - a ênfase pragmática nos resultados - que parece substituir a ênfase clássica na conversão, na mesma medida em que as manifestações substituem os argumentos. A Gaia da Nova Era, por sua vez, pode servir de um exemplo entre outros, surgido alhures, daquilo a que estamos nos referindo, não só em óbvia relação com a globalização, mas possuindo também a propriedade isomórfica de atravessar diversos campos.

Em todos os casos, enfim, a ênfase no Espírito pareceria consistir em um formidável recurso cultural justamente para desrespeitar os padrões culturais estabelecidos, criando conexões e misturas surpreendentes. Revela, sobretudo em tempos de "globalização", uma capacidade cada vez mais ampla de renovação "caótica" (outro significante que atravessa domínios), à frente da percepção por parte dos seguidores da coruja de Minerva. Uma aparente insensibilidade à cultura (denunciável, por exemplo, no campo missionário) ocultaria - mesmo que em estado "sel- 
vagem" - ações geradoras de cultura e uma outra noção de cultura, bem pouco "fundamentalista" considerada na perspectiva da globalização. Poder-se-ia negar, por exemplo, que a ênfase material e simbólica na questão do dinheiro ao mesmo tempo corresponde e produz uma ênfase e uma linguagem dos nossos tempos? E que o mesmo poderia ser dito da utilização plena dos recursos da mídia e das expressões musicais disponíveis? Nesse contexto, o estabelecimento de vínculos e influências concretas entre as várias tendências que confluem não deve substituir a sensibilidade para o significado geral presente, que pode por vezes não ter uma genealogia detectável.

O reconhecimento de que a globalização não é estranha a todas essas tendências poderá implicar, para as suas relações com o desenvolvimento e a modernização, uma possibilidade de ultrapassar as referências usuais, teleológicas, evolucionistas, ocidentalistas. Sobretudo na medida em que reconheçamos desenvolvimento e modernização como valores, as historicidades e o telos envolvidos não sendo exteriores às narrativas sociais, como é costume se tratar. Transmutar-se-ia, pois, finalmente, a função de perspectiva na de horizonte. Esta, aí sim, seria hoje intransponível enquanto recurso cultural, metáfora e embocadura diante da qual até a auto-reflexão teria de se render. J ustamente através desse relacionamento se desvendaria, então, o pleno significado da globalização, revestido - sempre como narrativa - dos elementos de exterioridade, superioridade e (posto que tratada como horizonte) anterioridade usualmente associados ao sagrado, inclusive em sua forma demoníaca. Poder-se-ia vislumbrar esse conjunto como nostalgia que não exclui a contingência, paisagem escatológica (substitutiva, talvez) a meio caminho entre a metafísica da presença e a perda niilista de sentido (Gargani 1996). Sentido possível, sem fechamento, não constituindo um objeto, mas podendo fazer reinterpretar objetos e situações a partir de um desacordo entre o existente e o real, este assumido em todas as potencialidades de (re)constituição à luz do poder de refiguração mimética da linguagem em sua função expressiva de manifestação e proposição (e não simplesmente de representação) de mundo. Veemência ontológica da linguagem (Ricoeur 1995) que nada mais seria que o poder das palavras conhecido de pregadores e fiéis religiosos.

Esse desacordo e a dinâmica que abre possibilitariam, enfim, escapar à auto-referência que a identidade e a diferença, quando construídas dualisticamente e mesmo ao pretenderem combater o etnocentrismo, só fazem reforçar, na medida em que constituem alteridades fixas e opositivas, ao invés de vigorarem a partir de um reconhecimento mútuo de 
semel hança à luz de um tertium (exterior ou como voz interior) que permita movimento e reconciliação. Indicariam ao mesmo tempo mais e menos do que em geral se tem pretendido, sinal dos tempos através das "novidades" que encontramos ao nosso redor.

A globalização, sem ser sinônimo de totalidade, ocuparia a sua posição como o novo nome do desenvolvimento e da modernização que se querem universais. M as, agora, universais não mais como metafísica, nem - depois do momento pós-colonial - como projeto imposto, maliciosamente ou não, de determinado lugar; ou, inversamente, como simples oposição a este. Pode ser tratada como um jogo de linguagem permitido por interconexões concretas, como artefato e ao mesmo tempo como um mito com muitas versões. M as versões num sentido forte, que acentua a inseparabilidade entre o mito e seus usos. Usos que permitem reinterpretar 0 aqui e agora e, nesse contexto, poderão até reafirmar identidades e interesses particulares, não autorizando nenhuma ingenuidade que ignore as realidades de poder envolvidas. Os discursos sobre a globalização serão outras tantas apropriações e leituras em face do mito, que constituem formas de ação e de objetificação diante das quais não é possível se omitir. E que não excluem a possibilidade de versões contra-hegemônicas do mito, quer por seu conteúdo, quer pelo lugar de onde são emitidas.

No entanto, as diversas versões parecem sempre buscar fazer referência, de uma forma ou de outra, à humanidade (quando não, sobretudo em versões mais místicas, aos seres em geral ), que, nesse sentido, pode, enfim, ser "corretamente" reafirmada, até, talvez, em nossas teorias antropológicas. Embora, nessa reconstituição, não se possa deixar de passar por uma rede diferenciada que faz com que se organizem objetificações - e, na hipótese positiva, instâncias - intermediárias, são essas que tornariam (ou não), eventualmente, um Obeyesekere mais próximo dos havaianos do que um Sahlins, ou os brasileiros (ou os latino-americanos) capazes de desenvolver uma competência especial na intermediação de alguns encontros específicos entre o primeiro e o terceiro mundos. A referência global, acentuando o sentido comunicativo, pode constituir uma esperança de que se recoloque o significado das objetificações, reduzindo a sua carga ideológica.

Estaríamos pela primeira vez diante de um mito global sem a muleta dos arquétipos e a priori - que descartam um esforço de construção-, podendo assumir-se como artefato, inseparável da ação humana: o próprio mito da globalização. E sem que tenham de ser ocultados todos os profundos e dramáticos conflitos, presentes sobretudo na medida em que a globalização, absolutamente, não produziu a eqüidade. Pelo contrário, 
são os conflitos que tornam o mito pragmaticamente real, permitindo que se mantenha a referência a um "outro" que não nega a matéria dos embates ordinários, antes se nutre dela, reafirmando, também aqui, não estarem o lugar do bem e o do mal dados de uma vez por todas. E ao mito e suas versões, por sua vez, corresponderiam rituais através de cuja linguagem essa referência - bem como a inseparabilidade entre o mito (o que se diz), a sua produção (quem diz) e os seus usos (como e para que se diz) - pode ser expressa, performatizada, reforçada e até propiciada. Com perdão da paráfrase, talvez não fosse ocioso lembrar - na linha de reflexão de Victor Turner - que justamente onde avultam os conflitos, superabundam os rituais.

Esses rituais teriam de ser identificados e examinados, mas pode-se apostar com grau razoável de certeza que entre eles se incluiriam reuniões e seminários acadêmicos; por suposto, sobretudo quando são internacionais e pretendem tratar da globalização. E esse talvez fosse um bom exemplo para nós dessa dimensão tomada em seu sentido afetivo, sem cuja apreciação dificilmente escaparíamos de uma visão cética ou cínica (no sentido banal) de nossas próprias atividades.

As ciências sociais têm tido muita dificuldade em lidar com as questões da afetividade. Os próprios esforços desconstrucionistas se interrompem na constatação das objetificações sem chegar a apreciar o "mistério" da mobilização das "paixões" humanas, mesmo em torno de objetos de que o senso comum não ignora a natureza artificial. A admissão de que o termo (como qualquer outro, inclusive ritual) possa estar encobrindo realidades culturais diversas, bem como a vontade de superação dos dualismos (no caso, do gênero racional-afetivo) (Velho 1995b), não parece mais ser retoricamente suficiente para afastar a questão. A recusa à generalização, aqui como alhures, quando não se deva a um escrúpulo político, talvez ainda esteja associada à manutenção de uma perspectiva "realista", de fato não se praticando a liberdade advinda do reconhecimento de que nossas descrições não são externas àquilo que descrevem, a própria "complexidade" fazendo parte de uma narrativa e de um vocabulário, e não de uma realidade paralisante. Hoje, porém, são tempos em que a experiência e os efeitos parecem assumir estatuto, por assim dizer, estrutural e comunicacional, a ponto de no terreno da religiosidade serem associados - como é constatado por Dupront (1993) - à relação que é privilegiada com o transcendente. No caso dos pentecostais, justamente, ganham, inclusive, um papel socializador e um estatuto ritual estratégicos por via do testemunho, prática discursiva que reconcilia corpo e espírito de um modo inesperado para quem se detenha exclusivamente na 
sua ênfase no espírito. A noção de testemunho, aliás, seria talvez eventualmente aplicável a outros domínios, como parece ser o caso na manutenção sem restrição do mecanismo das reuniões acadêmicas em plena era do correio eletrônico, mesmo quando não são reconhecidas as dimensões de desejo e vontade envolvidas.

Valeria a pena lembrar que o Espírito de Pentecostes se manifestaria não pelo retorno a uma única língua, mas pela capacidade de comunicação em todas elas. A antropologia, se precisa manter uma tensão com os discursos "nativos", deve também manter a sensibilidade e mesmo uma vulnerabilidade em relação a eles. É justamente o que torna essa tensão duplamente complexa, dinâmica, instigante e, talvez, exemplar para o próprio modo de tratamento da questão dos dualismos. Essa questão, aliás, ela própria também não deveria ser objetivada, mas sim reconhecida em seus significados polêmicos, temporais e práticos.

A globalização, evidentemente, tem de estar sujeita a outros tratamentos além do que está sendo proposto aqui, cuja função seria a de chamar a atenção para um pano de fundo do qual se supõe que o reconhecimento tenha conseqüências. Outros tratamentos, tal como na constituição operacional de objetos como os circuitos financeiros; as relações entre organismos eclesiais e paraeclesiais internacionais e seus congêneres locais, subentendidas na discussão acima sobre os pentecostais; a circulação de mercadorias, povos e indivíduos; o efeito dos estados concretos de dominação sobre o padrão de inserção internacional dos diversos países e regiões; a expansão das ideologias; as questões de meio ambiente; as redes de comunicação; e a constituição de brokers da globalidade, tal como pode vir a ser, no jogo das diferenças e das semelhanças, a vocação da A mérica Latina em geral e do Brasil em particular, com sua diversidade e os seus sincretismos. Sem falar de outros temas, aparentemente menos nobres, mas extremamente reveladores em sua linguagem. É o caso da combinação, no mundo do futebol, aparentemente sem nenhum sentimento reativo por parte da maioria dos torcedores e jogadores (embora a verificação disso já deva ser parte da investigação), do fervor patriótico, que continua representado pelas seleções nacionais, com a presença forte - e igualmente capaz de mobilizar entusiasmo e emoção - de equipes (e patrocínios) multinacionais, por sua vez, seguidamente, tendo como núcleo aglutinador dos aficcionados uma base de sentimentos locais e, mesmo, de nacionalidades (re)emergentes num contexto multicultural.

Porém, essa constituição de objetos deve ser vista como ela mesma representando a organização de formas de ação; a recíproca sendo igual- 
mente verdadeira e tudo isso tornando por vezes bastante ingênuo e desconhecedor de suas próprias motivações o modo pelo qual se costuma fazer o reclamo cientificista por rigor, clareza e objetividade. Uma vez que seja reconhecido como parte desses desenvolvimentos mais gerais, pode-se resgatar o sentido da globalização que aqui vem sendo trabalhado. Bom para pensar, mas também associável ao desejo, à vontade, ao imaginário, ao sagrado e às ênfases, excessos, flutuações e nulidades do significante - para listar apenas alguns termos associados a essa fugidia questão - enquanto constitutivos da própria práxis social. Constitutivos da práxis não só como nos exemplos mencionados acima, mas, também, no consumo de objetos polissêmicos; na formulação e implementação de estratégias, agendas e projetos políticos; e na apreciação coletiva dos universais e particulares, que fluem e se combinam, sem teorização, até mesmo na linguagem dos gestos e das palavras do ritual coreográfico do noticiário meteorológico televisivo global.

Esse sentido talvez seja mais decisivo nos seus traços incompletos que as presenças incisivas de fundamentos do mundo que buscam ocultar ou, mesmo, exorcizar a negatividade. Não sendo sólido, pode não se desmanchar no ar. Porém, ao mesmo tempo, não precisa transformar o reconhecimento da contingência numa celebração socialmente vazia da falta de sentido.

Recebido em 6 de agosto de 1996

A provado em 19 de setembro de 1996

Otávio Velho é professor-titular do Programa de Pós-Graduação em Antropologia Social (PPGAS) do M useu Nacional/UFRJ ; foi presidente da Associação Nacional de Pós-Graduação e Pesquisa em Ciências Sociais (Anpocs). 


\section{Nota}

* Texto apresentado em sua forma original ao seminário internacional Pluralismo Cultural, I dentidade e Globalização organizado pelo senior board do Conselho Internacional de Ciências Sociais da UNESCO (Rio de J aneiro, abril de 1996). Agradeço a A mir Geiger, Clara Mafra, André M ello, Patricia Birman e Paulo Britto pelos comentários e sugestões.

\section{Referências bibliográficas}

COSTA LIMA, Luiz. 1995. Vida e M imesis. Rio de J aneiro: Editora 34.

DUPRONT, Alphonse. 1993. Puissances et Latences de la Religion Catholique. Paris: Éditions Gallimard.

GARGANI, AIdo. 1996. “L'Expérience Religieuse comme Événement et Interprétation". In: J . Derrida e G. Vatimo (orgs.), La Religion. Paris: Éditions du Seuil. pp. 123-150.

OBEYESEKERE, Gananath. 1992. The A potheosis of Captain Cook: European Mythmaking in the Pacific. Princeton: Princeton University Press.

RICOEUR, Paul. 1995. Réflexion Faite. Paris: Éditions Esprit.

SAHLINS, Marshall. 1982. "The A potheosis of Captain Cook". In: M. Izard e P. Smith (orgs.), Between Belief and Transgression. Chicago: The University of Chicago Press. pp. 73102.

. 1995. How Natives Think. Chicago: The University of Chicago Press. VELHO, Otávio. 1995a. “N ovas Perspectivas: Globalização”. In: Besta-Fera: Recriação do M undo. Rio de J aneiro: Ed. Relume-Dumará.

. 1995b. "Considerações (In)Tempestivas sobre Nietzsche e Weber". In: Besta-Fera: Recriação do M undo. Rio de J aneiro: Ed. Relume-Dumará.

. 1996. "Religião e Política”. Cadernos de Conjuntura, 54. Rio de J aneiro: luperj. pp. 1-4. 


\section{Resumo}

O artigo procura abordar a temática da globalização fazendo apelo a um quadro antropológico de referências, sobretudo à idéia de mito. Ao mesmo tempo, procura explorar as relações da globalização enquanto perspectiva e enquanto mito (em contraste com a globalização como objeto) com um "espírito de época" que se manifestaria transversalmente em diversos domínios, tanto de saberes quanto de práticas sociais em geral. Privilegia o campo da religiosidade e a própria prática antropológica como pontos de entrada para captar esse "espírito de época".

\section{Abstract}

This article approaches the theme of globalization through a framework of anthropological references, especially the notion of myth. M eanwhile, it explores the relations between globalization as perspective and globalization as myth (as opposed to globalization as object), with a "spirit of epoch" manifested transversally in various domains, both in forms of knowledge and social practices in general. It focuses on the field of religiosity and anthropological practice itself as points of entry for capturing this "spirit of epoch". 